\title{
Role of lipid profile in early second trimester for prediction of pre-eclampsia
}

\author{
Surbhi*, Bangali Majhi \\ Department of Obstetrics and Gynecology, ABVIMS and Dr RML Hospital, New Delhi, India
}

Received: 19 June 2021

Accepted: 13 July 2021

\author{
*Correspondence: \\ Dr. Surbhi, \\ E-mail: surbhi17surbhi@gmail.com
}

Copyright: $\odot$ the author(s), publisher and licensee Medip Academy. This is an open-access article distributed under the terms of the Creative Commons Attribution Non-Commercial License, which permits unrestricted non-commercial use, distribution, and reproduction in any medium, provided the original work is properly cited.

\begin{abstract}
Background: The aim of the study was to determine association of abnormal lipid profile in early second trimester (14 to 20 weeks) with development of pre-eclampsia.

Methods: A prospective observational study included 260 women between 14-20 weeks of pregnancy attending a tertiary care Hospital in New Delhi. Serum lipid profile analysis was performed at the time of enrolment and cohort was followed up for occurrence of pre-eclampsia till 48 hours after delivery. Outcomes measured were difference in mean lipid levels in study (abnormal lipid profile) and control group (normal lipid profile) and accuracy of abnormal lipid profile to predict pre-eclampsia.

Results: The incidence of pre-eclampsia in our study was $11.13 \%$. The mean serum total cholesterol was significantly higher in pre-eclampsia group $(199.74 \mathrm{mg} / \mathrm{dl}$ vs $171.7 \mathrm{mg} / \mathrm{dl}$; $\mathrm{p}<0.05)$. The difference in mean triglyceride, HDL, VLDL and LDL levels between two groups was not significant. Total cholesterol has $44.83 \%$ sensitivity, $84.85 \%$ specificity, 27.08\% PPV, 92.45\% NPV with diagnostic accuracy of $80.38 \%$ in predicting pre-eclampsia (with $0.65 \%$ AUC with $95 \%$ confidence interval). While VLDL has maximum sensitivity of $68.97 \%$ while HDL has maximum specificity of $86.15 \%$ in predicting pre-eclampsia.

Conclusions: Abnormal total cholesterol levels have diagnostic accuracy of $80.38 \%$ to predict pre-eclampsia and abnormal lipid profile in early second trimester is a simple, non-invasive and economical test for prediction of preeclampsia.
\end{abstract}

Keywords: Cholesterol, HDL, LDL, Pre-eclampsia, Triglyceride, VLDL

\section{INTRODUCTION}

Hypertensive disorders of pregnancy occur in about $10 \%$ of all pregnant women around the world. Pre-eclampsia affects $3-5 \%$ of pregnancies. $^{1}$ According to the International Society for the study of Hypertension in pregnancy (ISSHP), hypertension is defined as a systolic blood pressure $>140 \mathrm{mmHg}$ and/or a diastolic blood pressure $>90 \mathrm{mmHg}$. A rise in the systolic blood pressure of $30 \mathrm{mmHg}$ or a rise in the diastolic blood pressure of 15 $\mathrm{mmHg}$ at least 4 hours apart or a single diastolic blood pressure $>110 \mathrm{mmHg}$ is also considered as hypertension.

The early identification of pregnancies at risk of preeclampsia permits prophylactic intervention with aspirin which has been found to reduce the risk of early preeclampsia, intrauterine growth restriction and preterm birth by improving disordered placentation. ${ }^{2}$ It may also enhance the development of new strategies for antenatal monitoring, to detect disease earlier and intervene timely to improve maternal and perinatal outcome.

Thus, so many markers have been proposed as predictors of pre-eclampsia such as Roll over test, angiotensin sensitivity test, mean arterial pressure (MAP), raised uric acid, Raised serum beta hCG at 14-20 weeks of gestation, alpha fetoprotein (AFP), estriol levels, pregnancy associated protein A (PAPP A), inhibin A levels, activin A, placental protein 13 , corticotrophin releasing hormone, uterine artery Doppler, platelet count, fms- like tyrosine 
kinase receptor-1 (sFlt-1), endoglin plasminogen activator inhibitor (PAI), neurokinin B, p-selectin, decreased levels of pro-angiogenic factors that includes vascular endothelial growth factors (VEGF), placental growth factor (PLGF), endothelial adhesion molecules, C-reactive proteins. ${ }^{4-11}$ Lipid profile as a predictor of preeclampsia is attributed to the metabolic alterations and risk factors which are similar in pre-eclampsia and arthrosclerosis and this might suggest a common pathophysiology. Physiological hyperlipidaemia of pregnancy increases by two-fold in preeclampsia. Abnormal lipoproteins levels are responsible for damage to endothelium that leads to high blood pressure, and proteinuria; which are important signs of preeclampsia. Association of serum lipids with pre-eclampsia was highly suggestive of a role for lipid profile analysis as a diagnostic tool. Therefore, detection of dyslipidaemia in early pregnancy could be used as a diagnostic tool in early prediction of pre-eclampsia, decreasing the lag time and preventing the maternal and neonatal morbidity and mortality.

The aim of the study was to evaluate the association of abnormal lipid profile in early second trimester (14 to 20 weeks) with development of pre-eclampsia and its prevalence in low-risk pregnancy.

\section{METHODS}

A prospective observational study was conducted on 260 pregnant women, in the department of obstetrics and gynaecology of ABVIMS and Dr. RML Hospital, a tertiary care teaching hospital in New Delhi, India over a period of one year and was approved by institutional ethics committee. Inclusion criteria included gestational age at 14 to 20 weeks irrespective of their parity and age between 18 to 35 years. Exclusion criteria included patients with diabetes mellitus, chronic hypertension or any other cardiovascular disease, smoker, history of renal disease, liver disease or other history of prior medical illness, thyroid disorder, multiple gestation and BMI $>25 \mathrm{~kg} / \mathrm{m}^{2}$.
At enrolment, 14 to 20 weeks two groups were made based on lipid profile abnormalities i.e.; normal lipid levels (group X) and abnormal lipid levels (group Y) (even a single deranged lipid level was considered as abnormal lipid profile).

They were followed up till 48 hours after delivery and 4 subgroups were made in postpartum (at the end of study). After correlation of group $\mathrm{X}$ and $\mathrm{Y}$, on the basis of normal and abnormal lipid profile with development of preeclampsia, the results were divided into 4 subgroups (group a, b, c, d) as follows- (a) group a: pre-eclampsia normal lipid profile; (b) group b: normotensive normal lipid profile; (c) group c: normotensive abnormal lipid profile; and (d) group d: pre-eclampsia abnormal lipid profile.

The normal values of lipid profile considered in the study were: total cholesterol- 176-299 mg/dl, high-density lipoprotein (HDL)- 52-87 mg/dl, low-density lipoprotein (LDL)- 77-184 mg/dl, very low-density lipoproteins (VLDL)- 13-23 mg/dl, triglyceride- $75-382 \mathrm{mg} / \mathrm{dl} .{ }^{12}$

Pre-eclampsia defined as hypertension after 20 weeks of gestation with new onset proteinuria Or in the absence of proteinuria, new-onset hypertension with the new onset of any of the following: (a) thrombocytopenia: platelet count less than 1 lakh; (b) renal insufficiency: serum creatinine concentrations greater than $1.1 \mathrm{mg} / \mathrm{dl}$ or a doubling of the serum creatinine concentration in the absence of other renal disease; (c) impaired liver function: elevated blood concentrations of liver transaminases to twice normal concentration; (d) pulmonary edema; (e) new-onset headache unresponsive to medication and not accounted for by alternative diagnoses or visual symptoms.

All the subjects were normotensive at the time of enrolment and followed up till 48 hours after delivery for the development of pre-eclampsia.

Total no. of patients at 14 to 20 weeks gestation (260)

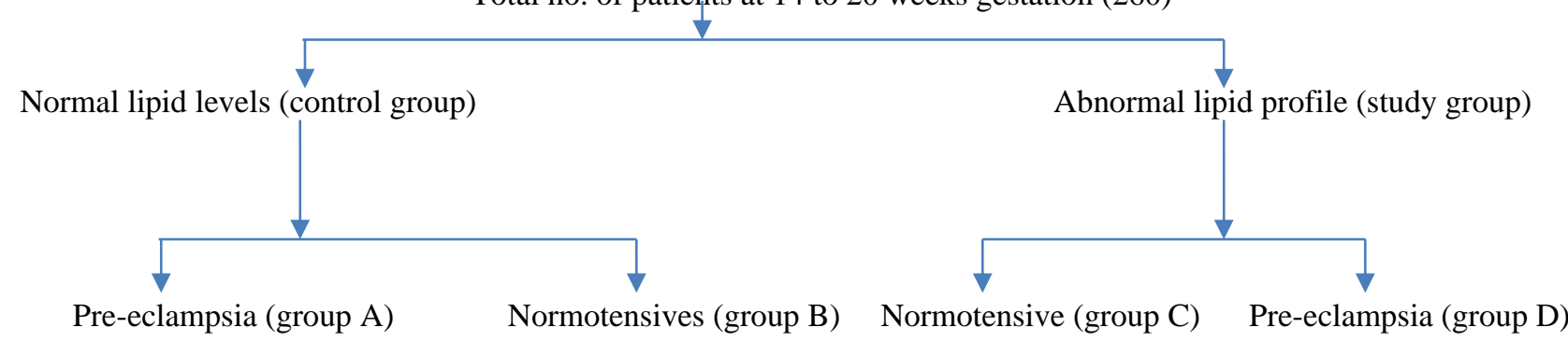

Figure 1:

Group a: pre-eclampsia normal lipid profile; group b: normotensive normal lipid profile; group c: normotensive abnormal lipid profile; group d: pre-eclampsia abnormal lipid profile. Pre-eclampsia study group: a+d (normal and abnormal lipid profile pre-eclampsia study groups), control group: $\mathrm{b}+\mathrm{c}$ (normal and abnormal lipid profile normotensive groups). All women underwent routine clinical evaluation, management and were followed up till 48 hours after delivery and relevant data entered in predefined structured proforma. 
The data was entered in MS excel spreadsheet and statistical analysis was done using Statistical Package for Social Sciences (SPSS) version 21.0.

\section{RESULTS}

Total 260 women participated in study after applying inclusion and exclusion criteria and were followed up till 48 hours after delivery and there were no lost to follow up.

The overall incidence of preeclampsia in the study was $11.15 \%(\mathrm{~N}=29)$. Lipid profile was found to be normal (group X) in 50 patients $(23.8 \%$ ) and abnormal (group Y) in 210 patients $(80.7 \%)$. The incidence of preeclampsia in study group $13.33 \%$ (28/210) and control group was $2 \%$ $(1 / 50)$.

Baseline characteristics data is shown in Table 1.

Table 1: Distribution of baseline characteristics.

\begin{tabular}{|ll|}
\hline Baseline characteristics & Mean \pm SD (range) \\
\hline $\begin{array}{l}\text { Age } \pm \text { at enrolment (years) } \\
27.52 \pm 3.7(19-35)\end{array}$ \\
\hline $\begin{array}{l}\text { Gestational age at blood } \\
\text { sampling (weeks) }\end{array}$ & $16.97 \pm 1.57(14-20)$ \\
\hline $\begin{array}{l}\text { Systolic blood pressure at } \\
\text { enrolment (mmHg) }\end{array}$ & $110.92 \pm 8.97(90-130)$ \\
\hline $\begin{array}{l}\text { Diastolic blood pressure at } \\
\text { enrolment (mmHg) }\end{array}$ & $73.75 \pm 7.16(60-90)$ \\
\hline $\begin{array}{l}\text { Gestational age at birth } \\
\text { (weeks) }\end{array}$ & $38.1 \pm 1.56(27.80-41)$ \\
\hline Primigravida & $171(62.07 \%)$ \\
\hline
\end{tabular}

The incidence of preeclampsia was not statistically significant ( $\mathrm{p}$ value $<0.05)$ between primigravida $(62.07 \%)$ as compared to $37.93 \%$ multigravida patients. Past history of pre-eclampsia was present in $45.45 \%$ of pre-eclamptic which was significantly higher as compared to normotensive group $(3.80 \%)$ (p value $=0.005)$.
Significant difference was seen in the distribution of total cholesterol $(\mathrm{mg} / \mathrm{dl})$ between preeclamptic and normotensive group. ( $\mathrm{p}$ value $<0.05$ ), total cholesterol $(\mathrm{mg} / \mathrm{dl})$ was deranged in $44.83 \%$ of pre-eclampsia patients which was significantly higher as compared to normotensive patients (15.15\%). No significant difference was seen in distribution of HDL, LDL, triglyceride and VLDL between preeclamptic and normotensive group as shown in Table 2.

The lipid profile parameters were not normally distributed. Thus, non-parametric test (Kruskal Wallis test; Chi square test) was used for the comparison. Significant difference was seen in total cholesterol $(\mathrm{mg} / \mathrm{dl})$, triglyceride $(\mathrm{mg} / \mathrm{dl})$, VLDL (mg/dl), LDL (mg/dl) between different sub-groups $(\mathrm{a}, \mathrm{b}, \mathrm{c}, \mathrm{d})(\mathrm{p}$ value $<0.05)$. No significant difference was seen in HDL $(\mathrm{mg} / \mathrm{dl})$ between different groups ( $p$ value>0.05) (Table 3 ).

VLDL (mg/dl) had sensitivity of $68.97 \%$ followed by triglyceride $(\mathrm{mg} / \mathrm{dl})(55.17 \%)$, total cholesterol $(\mathrm{mg} / \mathrm{dl})$ (44.83\%), LDL (mg/dl) (34.48\%). HDL (mg/dl) had specificity of $86.15 \%$ followed by total cholesterol (mg/dL) $(84.85 \%)$, LDL (mg/dl) $(69.70 \%)$, triglyceride $(\mathrm{mg} / \mathrm{dl})(50.65 \%)$ as shown in Table 4.

In prediction of pre-eclampsia, HDL $(\mathrm{mg} / \mathrm{dl})$ had lowest sensitivity of $17.24 \%$ and VLDL $(\mathrm{mg} / \mathrm{dl})$ had lowest specificity of $46.75 \%$.

Highest positive predictive value was found in total cholesterol (mg/dl) (27.08\%) and highest negative predictive value was found in total cholesterol $(\mathrm{mg} / \mathrm{dl})$ $(92.45 \%)$. We compared gestational age at the time delivery between pre-eclampsia and normotensive group and found that patients with pre-eclampsia had higher preterm birth $(44.83 \%, \mathrm{~N}=13)$ than control group $(12.12 \%$, $\mathrm{N}=28) \quad$ which was statistically significant (p value $<0.0001)$.

Table 2: Comparison of lipid profile (mg/dl) between preeclamptic and control groups.

\begin{tabular}{|llll|}
\hline Lipid profiles & Mean values \pm SD & & Normotensive $(\mathbf{N}=\mathbf{2 3 1})$ \\
\hline Total cholesterol & Pre-eclampsia $(\mathbf{N}=\mathbf{2 9})$ & $171.56 \pm 28.85$ & P value \\
\hline HDL & $199.74 \pm 54.31$ & $49.24 \pm 11.69$ & 0.0001 \\
\hline LDL & $48.29 \pm 9.23$ & $84.14 \pm 28.68$ & $>0.05$ \\
\hline Triglyceride & $88.17 \pm 27.22$ & $151.49 \pm 41.1$ & $>0.05$ \\
\hline VLDL & $193.03 \pm 99.23$ & $37.08 \pm 31.62$ & $>0.05$ \\
\hline
\end{tabular}

Table 3: Comparison of lipid profile between different sub-groups.

\begin{tabular}{|lllllll|}
$\begin{array}{l}\text { Lipid profile } \\
(\text { Mean } \pm \text { SD) }(\mathbf{m g} / \mathbf{d l})\end{array}$ & $\begin{array}{l}\text { Group A } \\
(\mathbf{N}=\mathbf{1})\end{array}$ & $\begin{array}{l}\text { Group B } \\
(\mathbf{N}=49)\end{array}$ & $\begin{array}{l}\text { Group C } \\
(\mathbf{N}=182)\end{array}$ & $\begin{array}{l}\text { Group D } \\
(\mathbf{N}=\mathbf{2 8})\end{array}$ & Total & P value \\
\hline Total cholesterol & $186 \pm 0$ & $158.95 \pm 19.44$ & $174.95 \pm 30.05$ & $200.23 \pm 55.24$ & $174.7 \pm 33.72$ & 0.0003 \\
\hline HDL & $55 \pm 0$ & $53.19 \pm 8.3$ & $48.18 \pm 12.25$ & $48.05 \pm 9.3$ & $49.14 \pm 11.43$ & 0.081 \\
\hline Triglyceride & $145 \pm 0$ & $114.1 \pm 23.99$ & $161.55 \pm 38.91$ & $194.74 \pm 100.61$ & $156.12 \pm 52.31$ & $<0.0001$ \\
\hline VLDL & $21.1 \pm 0$ & $22.97 \pm 4.78$ & $40.87 \pm 34.58$ & $52.37 \pm 36.58$ & $38.66 \pm 32.42$ & $<0.0001$ \\
\hline LDL & $58.6 \pm 0$ & $71.07 \pm 14.93$ & $87.66 \pm 30.46$ & $89.22 \pm 27.11$ & $84.59 \pm 28.5$ & $<0.0001$ \\
\hline
\end{tabular}


Table 4: Sensitivity, specificity, PPV and NPV of lipid profile for predicting preeclampsia.

\begin{tabular}{|lllllll|}
\hline Variables & Sensitivity (\%) & Specificity (\%) & AUC & PPV (\%) & NPV (\%) & $\begin{array}{l}\text { Diagnostic } \\
\text { accuracy (\%) }\end{array}$ \\
\hline Total cholesterol & 44.83 & 84.85 & 0.65 & 27.08 & 92.45 & 80.38 \\
\hline HDL & 17.24 & 86.15 & 0.52 & 13.51 & 89.24 & 78.46 \\
\hline Triglyceride & 55.17 & 50.65 & 0.53 & 12.31 & 90 & 51.15 \\
\hline VLDL & 68.97 & 46.75 & 0.58 & 13.99 & 92.31 & 49.23 \\
\hline LDL & 34.48 & 69.7 & 0.52 & 12.5 & 89.44 & 65.77 \\
\hline
\end{tabular}

\section{DISCUSSION}

Vidyabati et al shows that there is hypertriglyceridemia among the patients who subsequently developed preeclampsia. ${ }^{13}$ Their study also showed that total cholesterol, LDL, VLDL levels were also higher in preeclampsia women which was similar to our study. But the mean value of HDL for both the groups were similar in their study and similar result also seen in our study. They also concluded that with one unit increase in total cholesterol, triglycerides, VLDL and LDL the probability of developing PIH in pregnant women- $12.6 \%, 0.3 \%, 12.4 \%$ and $7.1 \%$ respectively. And with one-unit increase in HDL- $11.4 \%$ less chances of developing PIH

Ewa et al concluded that higher levels of triglycerides and remnant cholesterol in early pregnancy are associated with an increased risk of pre-eclampsia and sustained hypertension long term postpartum. ${ }^{14}$ Similarly, in our study early second trimester triglycerides value was higher in pre-eclampsia group than normotensive group, the $\mathrm{p}$ value being $<0.05$. HDL is statistically not significant in other studies like in ours such as in Yadav et al, Kumari et al, Siddiqui et al and many more studies. ${ }^{15-17}$

Iftikhar et al in the study relationship between leptin and lipids during pre-eclampsia found that severity of preeclampsia increases as levels of total cholesterol increases and which was higher due to raised leptin levels. ${ }^{18}$ They concluded that increased cardiovascular risk that has been linked to hyperleptinemia and significant correlation between serum leptin and total cholesterol ( $\mathrm{p}$ value $<0.05$ ) whereas relation with other lipid variables in not significant. Leptin levels were not included in our study.

Singh et al in their study found that the women with preeclampsia with poor fetal outcome had to be induced resulting in preterm deliveries, similar results were seen in our study. ${ }^{19}$ Post-partum eclampsia was higher in preeclampsia group $(17.24 \%$ vs $0 \%$; $p$ value $<0.0001)$ than in normotensive group. No mortality was seen from preeclampsia in the study.

Thus, estimation of maternal lipid profile in the early second trimester will bring about early recognition and allow better management of patients at risk of preeclampsia, before the clinical syndrome and complications of pre-eclampsia appear. Also, early treatment of such cases with aspirin can improve feto-maternal outcome.
The strength of our study includes its prospective design and the high follow-up rate. Several important limitations must be considered when interpreting the results of our study. First, only one sample has been taken for lipid profile measurement. It has been suggested by various studies that with lipid levels increased with increase in gestational age and serial monitoring may be more useful. Small sample size may hinder inferences from some of our analyses and large prospective studies are recommended. Third, although we compared for many potential confounders, we cannot exclude the possibility of the other confounding from unmeasured covariates. Finally, another limitation of the present study is that it was done in only one medical centre.

Our study evaluated role lipid profile estimation between 14-20 weeks pregnancy to predict pre-eclampsia and found that total cholesterol values are significantly increased in pre-eclampsia group ( $\mathrm{p}$ value $<0.05$ ). Accuracy of abnormal total cholesterol for prediction of pre-eclampsia was 80.38 . Significant difference was seen in the distribution of preterm deliveries between preeclamptic and normal study subjects ( $\mathrm{p}$ value $<0.05$ ). The detection of dyslipidaemia before 20 weeks of gestation is a simple, non-invasive and economical test for prediction of pre-eclampsia and would help us to recognise pregnancies at high-risk for preeclampsia even before the clinical syndrome.

\section{CONCLUSION}

The detection of dyslipidaemia before 20 weeks of gestation is a simple, non-invasive and economical test for prediction of pre-eclampsia and would help us to recognise pregnancies at high-risk for preeclampsia even before the clinical syndrome.

\section{Funding: No funding sources \\ Conflict of interest: None declared}

Ethical approval: The study was approved by the Institutional Ethics Committee

\section{REFERENCES}

1. Duley L. The global impact of pre-eclampsia and eclampsia. Semin Perinatol. 2009;33(3):130-7.

2. Gestational hypertension and preeclampsia. ACOG Practice Bulletin No. 222. American College of Obstetricians and Gynecologists. Obstet Gynecol 2020;135:237-60. 
3. Cunningham FG, Leveno KJ, Bloom SL, Dashe JS, Hoffman BL, Casey BM, et al. Williams Obstetrics. 25th ed. New York, NY: McGraw Hill;1918: 725.

4. Gant NF, Daley CL, Chand S, Whalley PJ, Macdonald PC. A study of angiogenesis II pressor response throughout primigravida pregnancy. J Clin Invest 1973;52:2682-9.

5. Page EW, Christianson R. The impact of mean arterial pressure in the middle trimester upon the outcome of pregnancy. Am J Obstet Gynecol. 1976;125(6):740-6.

6. Ales KL, Norton ME, Druzin ML. Early prediction of antepartum hypertension. Obstet Gynecol. 1989;73(6):928-33.

7. Cnossen JS, Ruyter H, Post JA, Mol BW, Khan KS, Riet G. Accuracy of serum uric acid determination in predicting pre-eclampsia: a systematic review. Acta Obstet Gynecol Scand. 2006;85(5):519-25.

8. Pouta AM, Hartikainen AL, Vuolteenaho OJ, Ruokonen AO, Laatikainen TJ. Midtrimester Nterminal proatrial natriuretic peptide, free beta $\mathrm{hCG}$, and alpha-fetoprotein in predicting preeclampsia. Obstet Gynecol. 1998;91(6):940-4.

9. Kang JH, Farina A, Park JH, Kim SH, Kim JY, Rizzo $\mathrm{N}$, et al. Down syndrome biochemical markers and screening for preeclampsia at first and second trimester: correlation with the week of onset and the severity. Prenat Diagn. 2008;28(8):704-9.

10. Festa A, Agostino R, Howard G, Mykkanen L, Tracy RP, Haffner SM. Chronic subclinical inflammation as part of the insulin resistance syndrome: the Insulin Resistance Atherosclerosis Study (IRAS). Circulation. 2000;102(1):42-7.

11. Aquilina J, Barnett L, Thompson O, Harrington K. Comprehensive analysis of uterine artery flow velocity waveforms for the prediction of preeclampsia. Ultrasound Obstet Gynecol 2000; 16:163-70.

12. Cunningham FG, Leveno KJ, Bloom SL, Dashe JS, Hoffman BL, Casey BM, et al. Williams Obstetrics. 25th ed. New York, NY: McGraw Hill;1918: 1259.

13. Vidyabati RK, Davina H, Singh NK, Singh W. Gyaneshwar-Serum $\beta$ hCG and lipid profile in early second trimester as predictors of Pregnancy induced hypertension. J Obstet Gynecol India. 2010;60(1):4450.

14. Ewa AM, Berry SA, Salama KM, Maghraby NY. Lipids and uric acid in midsecond trimester and prediction of adverse pregnancy outcome. Benha Med J. 2018; 35:145-9.

15. Yadav K, Aggarwal S, Verma K. Serum $\beta$ hCG and Lipid Profile in Early Second Trimester as Predictors of Pregnancy-Induced Hypertension. J Obstet Gynaecol India. 2014;64(3):169-74.

16. Kumari K, Singh U, Maharshi S, Singh R. Assessment of serum lipid profile in early pregnancy and its relation with pre-eclampsia: a prospective study. Int $\mathbf{J}$ Reprod Contracept Obstet Gynecol. 2016;5:840-4.

17. Siddiqui I. Maternal Serum Lipids in Women with Pre-eclampsia. Ann Med Health Sci Res. 2014;4(4):638-41.

18. Iftikhar U, Iqbal A, Shakoor S. Relationship between leptin and lipids during preeclampsia. J Pak Med Assoc. 2010;60(6):432-5.

19. Singh A, Kujur A, Jain P. Fetomaternal impact of altered lipid profile in pregnancy. Int $\mathbf{J}$ Reprod Contracept Obstet Gynecol. 2018;7:132-6.

Cite this article as: Surbhi, Majhi B. Role of lipid profile in early second trimester for prediction of preeclampsia. Int J Reprod Contracept Obstet Gynecol 2021;10:3101-5. 